\title{
A systematic data collection on chloride-induced steel corrosion in concrete to improve service life modelling and towards understanding corrosion initiation
}

\section{Introduction}

Chloride-induced corrosion of reinforcing steel in concrete is one of the most frequent deterioration mechanisms for concrete structures [1], causing high costs to society [2,3]. Despite this, the factors controlling corrosion initiation of steel in concrete are still poorly understood [4]. The established concept to tackle this problem in science and engineering is based on a chloride threshold value for corrosion, the socalled critical chloride content $\left(C_{\text {crit }}\right)$, where corrosion is assumed to occur as soon as the chloride concentration at the steel exceeds this threshold value. Literature reviews [5-9] revealed a huge scatter of values of $C_{\text {crit }}$, which is for a great part due to the wide variety of test methods used to determine $C_{\text {crit }}$, making it difficult to compare the results. Many of the literature results were obtained under laboratory conditions not representative for site conditions and are thus of little value for engineering purposes. In absence of practice-related data, the statistical distribution for $C_{\text {crit }}$ used in service life modelling can generally be traced to one single laboratory study [5]. Thus, there is a lack of statistical information on practice-related $C_{\text {crit }}$ (Fig. 1), e.g. $C_{\text {crit }}$ values that are measured on samples from real structures and in realistic conditions. However, this is exactly what is needed in probabilistic service life modelling.

Moreover, drawing conclusions on the main factors affecting corrosion initiation is difficult, as the experimental conditions in the literature differ strongly. Thus, analysing the literature remains a challenge, because it is difficult to rule out the possible influence of different experimental methods used in different studies. A better documentation of $C_{\text {crit }}$ and possible influencing factors (location of corrosion initiation with respect to the presence of defects at the steelconcrete interface, binder type, w/b-ratio, reinforcing steel properties, etc.) would significantly improve identifying the most dominant influencing factors for corrosion initiation.

\section{A systematic data collection on chloride-induced corrosion}

To this purpose a systematic collection of $C_{\text {crit }}$ values together with a detailed documentation of the conditions at the steel-concrete interface and the location of corrosion initiation was recently established [10]. All $C_{\text {crit }}$ reported in this data collection were measured with one experimental protocol. The data collection contains results from samples taken from by now 5 engineering structures. We consider it valuable that additional information about material properties of steel and concrete is also reported (steel microstructure, steel potential, depth of carbonation, concrete resistivity, binder type, etc.).

\subsection{Critical chloride content $C_{\text {crit }}$}

Due to the relatively high number of samples tested so far (in total
58 samples, on average $\sim 10$ per structure), the database allows the statistical treatment of $C_{\text {crit }}$ results, which is needed for probabilistic service life modelling (see Section 3). A regularly updated version of the data collection can be freely accessed on the repository in Ref. [10]. For a more detailed description of the methodology used to collect the data it is referred to Ref. [11].

It is important to note that all the compiled $C_{\text {crit }}$ values were determined with the same experimental method [12], thus ensuring comparability of the obtained results. This is important because the wide variety in experimental approaches used to measure $C_{\text {crit }}$ in the literature is one of the main factors that to date hampers the systematic analysis of literature data $[5-8,13]$. Using one defined protocol allows overcoming this severe limitation of the current literature, and will allow to investigate the influence of different parameters, such as the w/b-ratio, the binder type, the rebar type, and the many more parameters that have been suggested to play a role in corrosion initiation.

It is also worth pointing out that the used protocol [12] to determine $C_{\text {crit }}$ aimed at delivering as practice-related results as possible. This concerns the experimental test setup, electrochemical measurements, and the criterion to detect corrosion initiation. Most of the $C_{\text {crit }}$ reported in this data compilation were determined on reinforced concrete cores retrieved from engineering structures, thus guaranteeing realistic material conditions for concrete and steel $[10,11]$. The samples were tested with the protocol described in [12], that essentially consists of exposing a defined area of the reinforced concrete specimen to chloride solution while monitoring the corrosion potential of the embedded steel.

The test protocol [12] used to determine $C_{\text {crit }}$ was developed at ETH Zurich over the last years [14] and is to some extent based on the work of RILEM technical committee 235-CTC $[15,16]$. The aim during the development was to devise a test method that is capable of delivering realistic $C_{\text {crit }}$, viz. values that can be used in service life modelling.

\subsection{Inspection of the steel-concrete interface}

Upon corrosion initiation, the specimens were split to inspect the steel-concrete interface and to investigate the location of corrosion initiation with respect to any inhomogeneities at the steel-concrete interface. Thus in addition to $C_{\text {crit }}$ the data compilation contains a valuable systematic documentation of the location of corrosion initiation with respect to characteristics at the steel-concrete interface. Here, the effect of air voids and cracks at the steel-concrete interface and the influence of the non-carbonated cover depth on $C_{\text {crit }}$ were investigated. The "non-carbonated cover depth" is the distance between the carbonation front (determined with the phenolphthalein spray test [17]) and the steel surface.

This systematic documentation of conditions at the steel-concrete interface and the point where corrosion occurred intends to contribute 
SERVICE LIFE MODELLING

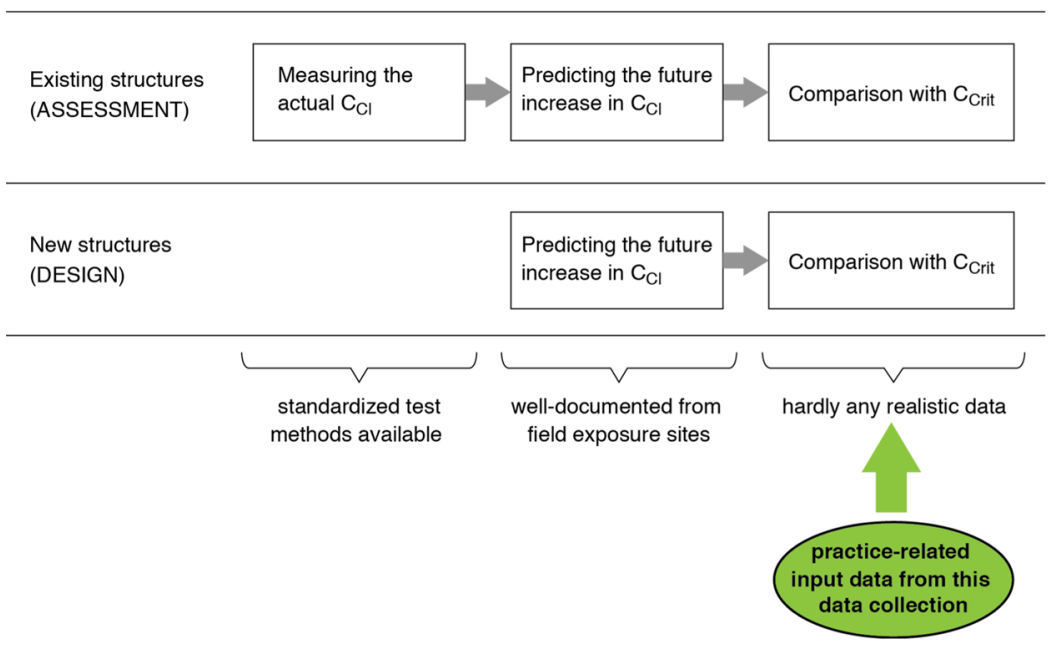

Fig. 1. Schematic illustration of service life modelling to predict the time of corrosion initiation for condition assessment and structural design. The time of corrosion initiation is reached when the actual chloride content $C_{\mathrm{Cl}}$ at level of reinforcement is equal or higher than the critical chloride content $C_{\text {crit }}$. The here presented database is providing realistic and significantly diverse input data for the model. to a better understanding of the influence of local conditions at the steel-concrete interface on corrosion initiation, which is one of the major open questions in the field of corrosion of reinforced concrete structures [18] (compare Section 3.2).

\subsection{Future application of the systematic data collection}

It is worth mentioning that the data collection will be continuously updated in the future as new results become available (currently, more than 50 additional samples are being tested). In addition to our own experimental data, we are open to consider results from other research groups (to be added to the database) given that scholars followed the experimental protocol and guidelines described in $[11,12]$. Thanks to the open access nature of the data collection, the research community can immediately start exploring and analyzing the data. This may range from revealing unexpected, simple relationships between parameters to more complicated, multi-parameter analyses, e.g. by statistical methods or with help of machine learning, which are approaches that can typically not be easily applied to literature data due to the strong biases arising from different test methods used by different authors. In the following sections, we illustrate how this systematic data collection may contribute to improving service life modelling and understanding corrosion initiation in concrete.

\section{Results and discussion}

\subsection{Utilizing the database of $C_{\text {crit }}$ for service life modelling}

\subsubsection{Significance of input parameters on service life modelling}

Predicting the time to corrosion initiation in concrete requires models to forecast over time the chloride content at a given depth, viz. the chloride content at the level of the embedded reinforcing steel $\left(C_{\mathrm{Cl}}\right)$. This numerical prediction of $C_{\mathrm{Cl}}$ is compared to $C_{\text {crit }}$. The time at which $C_{\mathrm{Cl}}>C_{\text {crit }}$ is the time of corrosion initiation, which is often considered the service life. Service life modelling is on the one hand important for condition assessment of existing structures, where, based on the actual chloride content on the steel surface, the remaining service life can be estimated (Fig. 1, [19]). On the other hand, modelling the time to corrosion onset is used for the design of new structures, namely to ensure the durability of these within the design service life (Fig. 1).

The existing models describing chloride ingress into concrete often rely on empirical approaches using equations resembling diffusion laws [20-23]. Due to the variability inherent to both chloride ingress and $C_{\text {crit }}$, it is often preferred to use full probabilistic service life model approaches, that allow to forecast the probability for corrosion initiation as a function of time. This requires that parameters for the chloride transport model - such as the chloride diffusion coefficient or the so-called ageing factor - as well as $C_{\text {crit }}$ are considered as stochastic variables.

Selection of the stochastic input parameters of the model describing transport of chlorides ions through the concrete, based on variables such as cement type and concrete mix proportions, is possible based on numerous long-term field studies reporting data on chloride ingress into concrete [23-27] (Fig. 1). However, there is almost no stochastic data available for $C_{\text {crit, }}$ particularly what concerns values representative for site-conditions [28]. The majority of the available laboratory experiments were conducted in solution or mortar rather than concrete, with smooth rather than ribbed steel and under often severely polarized conditions, which does not reflect realistic conditions. Thus it is common practice in service life modelling to use a unique distribution of $C_{\text {crit }}$ (often the one reported in the fib model code for service life design [22]), regardless of the type of structure and materials used.

\subsection{2. $C_{\text {crit }}$ values representative for site-conditions}

The novelty of this short communication are data on the critical chloride content from field structures. Fig. 2 shows examples of statistical distributions of $C_{\text {crit }}$ that can be found in the current version of the data collection [10]. The distributions shown are from 5 different structures in Switzerland: 4 tunnels (for 2 of those tunnels, samples were taken from 2 different structural members (different walls) each) and 1 bridge (in which samples are distinguished between horizontal and vertical rebars). This yields 8 different tested series of samples. For each series the different samples tested were taken within a small area of the structure $\left(<2 \mathrm{~m}^{2}\right)$. Thus the samples within one tested series were from presumably very similar material properties and exposure history. Despite this, Fig. 2 shows that the results can scatter over considerable ranges. Moreover, the value of $C_{\text {crit }}$ determined can significantly differ from one structure to another and also from the distribution stipulated in the fib model code for service life design [22].

\subsubsection{Methods for obtaining the statistical distribution of $C_{\text {crit }}$ and} modelling of service life

The experimental values for $C_{\text {crit }}$ reported in the data collection (Fig. 2) can be described by statistical distribution functions, in order to be used as input data for probabilistic service life modelling. To illustrate this, the lognormal-distribution (cumulative distribution function $C D F$ given in Eq. 1) was here used to describe the $C_{\text {crit }}$ measured in 5 structures as shown in Fig. 2, with its parameters detailed in Table 1:

$F_{x}(x)=\Phi\left(\frac{\ln x-\lambda}{\varepsilon}\right)$ 


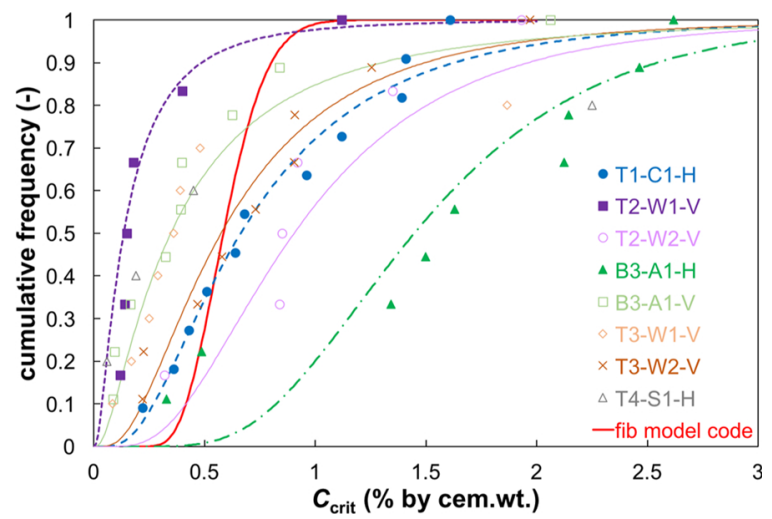

Fig. 2. Cumulative frequency of $C_{\text {crit }}$ for eight different elements from five structures. T1-C1 indicates samples retrieved from a tunnel (T) ceiling (C); T2-W1 indicates samples taken from a tunnel wall (W); B3-A1 stands for the abutment wall (A) of a bridge (B). The last letters in each series indicates whether the rebars were horizontally $(\mathrm{H})$ or vertically $(\mathrm{V})$ oriented in the structure. The lines between the symbols are the fitted lognormal-distributions with the parameters given in Table 1 . For comparison, also the distribution given in the fib model code for service life design [22] is plotted in red, which is a beta-distribution. The three lowest $C_{\text {crit-values }}$ for T2-W1-V were measured in already carbonated concrete (For interpretation of the references to colour in this figure legend, the reader is referred to the web version of this article.).

where $\lambda=\mu_{\ln x}$ and $\varepsilon^{2}=\sigma_{\ln x}^{2}$.

Modelling of the chloride ingress was conducted with the common empirical approach [29] (Eq. 2) to highlight the impact of using structure-dependent $C_{\text {crit }}$ on service life modelling. A constant set of input data for the chloride ingress was used (given in Table 2), but different distributions of $C_{\text {crit }}$.

$C(x, t)=C_{s} \times\left(1-\operatorname{erf}\left(\frac{x}{2 \times \sqrt{D_{a p p} \times t}}\right)\right)$

Here, $C(\mathrm{x}, \mathrm{t})$ describes the chloride content at depth $x$ and time $t, C_{\mathrm{s}}$ is the chloride surface concentration at the exposure side, and $D_{\text {app }}(t)$ the apparent chloride diffusion coefficient (shown in Eq. 3, age factor $n$ and reference diffusion coefficient $D_{\text {app,o }}$ given in Table 2).

$D_{a p p}(t)=D_{a p p, 0} \times\left(\frac{t_{0}}{t}\right)^{n}$

Depth $x$ corresponds to the cover depth, chosen for all structures as $50 \mathrm{~mm}$. The time to corrosion initiation is the time when $C(\mathrm{x}, \mathrm{t})$ equals $C_{\text {crit }}$

\subsubsection{Predicted time to corrosion initiation for site-conditions}

The probability of corrosion initiation was calculated for each field structure using its specific statistical distribution of the critical chloride content (Fig. 2, Table 1). The so calculated probability of corrosion initiation (Fig. 3) varies strongly for each different field structure, even if the same chloride ingress parameters are chosen. Depending on the considered structure, the predicted time to corrosion initiation can be significantly shorter or longer than the prediction assuming $C_{\text {crit }}$ as stipulated in the fib model code for service life design. Moreover, the example calculations shown in Fig. 3 indicate that $C_{\text {crit }}$ is likely to have a more dominant influence on the predicted time to corrosion initiation than the chloride transport properties. This highlights the decisive
Table 2

Parameters for the chloride ingress model example.

\begin{tabular}{llll}
\hline Parameter for all structures & & \\
\hline cover depth $(\mathrm{mm})$ & $x$ & 50 \\
\hline diffusion coefficient at reference time $t_{0}\left(\mathrm{~m}^{2} / \mathrm{s}\right)$ & $D_{a p p, o}$ & $2 * 10^{-12}$ \\
age coefficient $(-)$ & $n$ & 0.3 \\
surface chloride concentration (M-\% by cem.wt.) & $C_{\mathrm{s}}$ & 2 \\
\hline
\end{tabular}

influence of the $C_{\text {crit }}$ on the results of service life modelling, in agreement with other studies [30].

\subsubsection{Outlook for future service life modelling}

The continuously growing data compilation for $C_{\text {crit }}$ including corresponding material properties (concrete type, steel type, etc.) and structural details (age, exposure, etc.), will considerably broaden the array of available input data for service life modelling. We are confident that this will permit selecting more appropriate, viz. more realistic, model input values for $C_{\text {crit }}$ than the current approach of using tabulated unique values. Thus the predictive power of service life models will improve, as the input values are more practice-related.

\subsection{Towards understanding the influence of the steel-concrete interface on corrosion initiation}

Besides $C_{\text {crit }}$, the data compilation contains a systematic documentation of the location of corrosion initiation with respect to characteristics at the steel-concrete interface to study the influence of characteristics at the steel-concrete interface on the $C_{\text {crit }}$. To highlight this benefit, the example of the influence of air voids and the $\mathrm{pH}$ of the pore solution on the $C_{\text {crit }}$ is briefly discussed.

Table 1

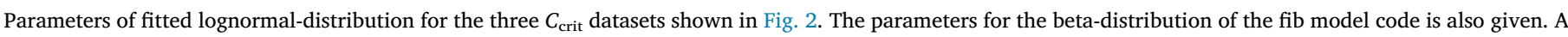
and $\mathrm{B}$ are the lower and upper border of the beta distribution, respectively.

\begin{tabular}{|c|c|c|c|c|c|c|c|}
\hline Parameter & T1-C1-H & T2-W1-V & T2-W2-V & B3-A1-H & B3-A1-V & T3-W2-V & fib model code [22] \\
\hline$\lambda$ & -0.41 & -2.0 & -0.1 & 0.37 & -1.06 & -0.55 & - \\
\hline$\varepsilon$ & 0.70 & 1.0 & 0.6 & 0.44 & 1.03 & 0.75 & - \\
\hline$\alpha$ & - & - & - & - & - & - & 5.3 \\
\hline$\beta$ & - & - & - & - & - & - & 18.6 \\
\hline A & - & - & - & - & - & - & 0.2 \\
\hline B & - & - & - & - & - & - & 2 \\
\hline
\end{tabular}




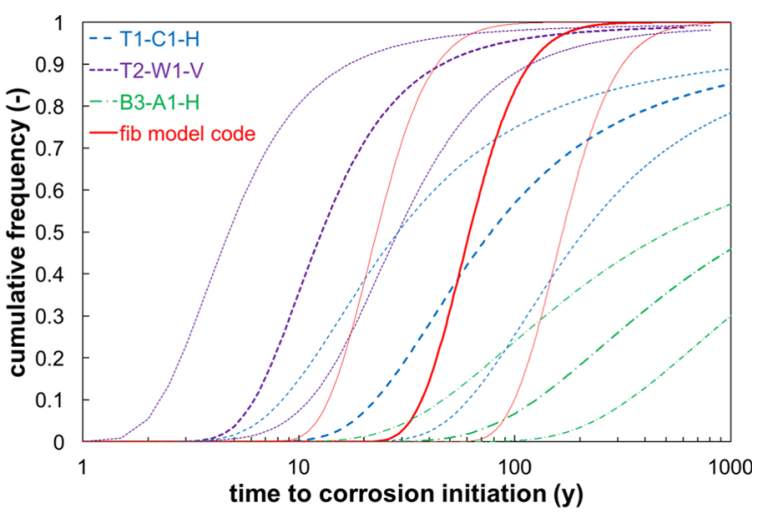

Fig. 3. The cumulative frequency of corrosion initiation vs. time for three different cases $\left(C_{\text {crit }}\right)$ shown in Fig. 2 . The chloride ingress was modelled with the error function and parameters given in Table 2. The area between the thinner lines shows the influence of the chloride ingress parameters (diffusion coefficient from Table 2 was varied by the factor 2 ).

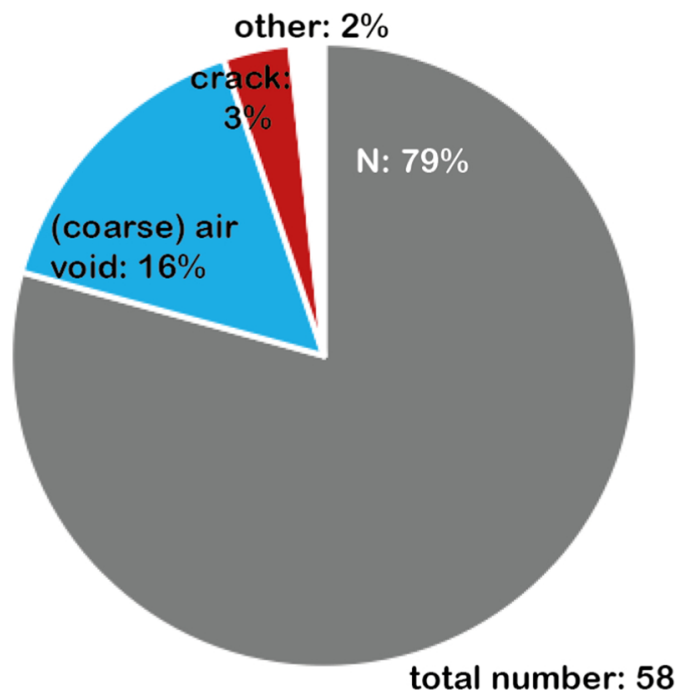

Fig. 4. The frequency of occurrence of corrosion initiation at different local conditions at the concrete interface. In $79 \%$ of the in total 58 evaluated cases, no irregularities were visually apparent at the location of corrosion at steel-concrete interface ( $\mathrm{N}$, dark grey). The blue colour indicates the portion of cases where corrosion initiated at a coarse air void. Only in a minority of cases did corrosion occur at cracks (red; here, cracks mean small cracks at the steel-concrete interface that are not expanding to the exposure side of the concrete sample) (For interpretation of the references to colour in this figure legend, the reader is referred to the web version of this article.).

3.2.1. Influencing parameters at the steel-concrete interface on $C_{\text {crit }}-$ air voids

The data in Fig. 4 shows that in most cases (approx. 80\%), no irregularities were visually apparent at the location of corrosion initiation at the steel-concrete interface. In approx. $20 \%$ of the cases, the corrosion spot was located at irregularities, including coarse air voids, cracks, or tie wires. Fig. 5 depicts the influence of these defects on the distribution of $C_{\text {crit. }}$ Interestingly, statistically significantly higher chloride contents (level of significance: $20 \%$ ) were needed to initiate corrosion at coarse air voids than at locations with no visually apparent irregularities at the steel-concrete interface. These results may appear to be in contradiction with other studies, where interfacial air voids are typically found as preferential sites for corrosion initiation [31,32]. This raises an important scientific question that still needs to be answered by further research. Current discussions in RILEM technical committee 262-SCI [18] have led to the hypothesis that this apparent disagreement can be explained by the moisture state of macroscopic voids. The air voids in concrete, exposed in splash water situations such as exposure regime XD3 [33] are generally not water-saturated [34]. It is hypothesized that in largely air-filled macroscopic voids, corrosion initiation is hardly possible due to the absence of an electrolyte. In this work, the concrete samples were exposed in solution, with merely short intervals of drying in the lab twice a year. The relative humidity (RH) in the concrete at the depth of the rebars was always between 95-98\% (measured with RH sensors in companion samples). This confirms that air voids were here unsaturated [34,35], which may explain the observation that coarse air voids were in the majority of cases not favourable locations for corrosion initiation (Figs. 4, 5).

\subsubsection{Influencing parameters at the steel-concrete interface on $C_{c r i t}-p H$ at the steel surface}

Fig. 6 shows a strong correlation between the non-carbonated cover depth and the $C_{\text {crit }}$. The $C_{\text {crit }}$ is increasing with increasing non-carbonated cover depth. This can be explained by the $\mathrm{pH}$ at the steel surface, which depends on how close the carbonation front has approached to the steel. The non-carbonated cover depth is an indirect indication of the $\mathrm{pH}$ of the pore solution at the level of reinforcement. This is because the $\mathrm{pH}$ is not decreasing immediately from $\mathrm{pH}>13$ to approx. 9 at the carbonation front, but shows a more gradual decrease [36]. Thus, also ahead of the carbonation front, the $\mathrm{pH}$ is lower than the initial highly alkaline value. The significance of the $\mathrm{pH}$ on chloride-induced corrosion initiation is discussed in Ref. [37]. The change of the $\mathrm{pH}$ influences the ratio between free and bound chlorides $[38,39]$, leading therefore to a higher concentration in free chlorides. Certainly, this increases the risk 


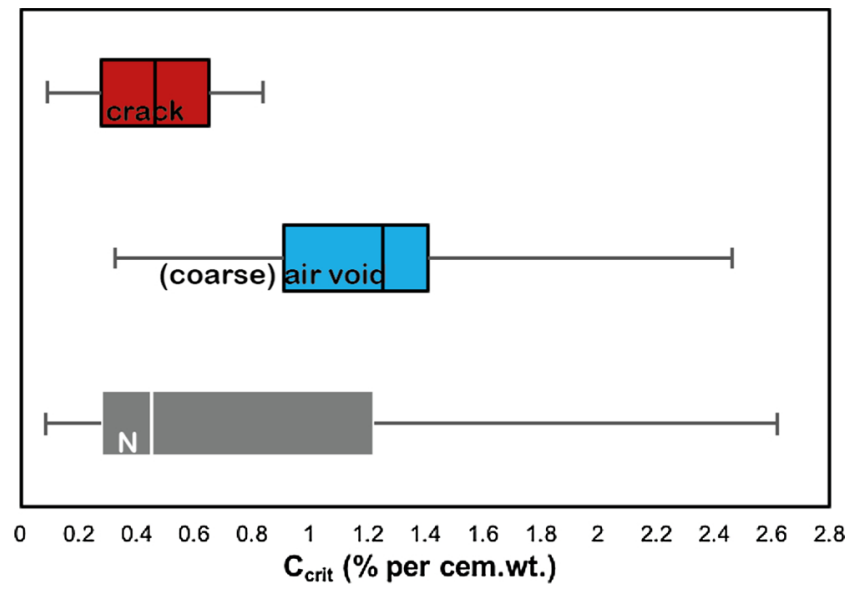

Fig. 5. Box plots of $C_{\text {crit }}$ for the 58 evaluated cases of corrosion initiation related to the steel-concrete interface characteristics (see Fig. 4 for terminology). The boxes indicate the $25 \%, 50 \%$, and $75 \%$-quantiles, and the whiskers are extreme values. For cracks (red) only two values were documented so far (For interpretation of the references to colour in this figure legend, the reader is referred to the web version of this article.).

for corrosion initiation for the same total chloride content.

\subsubsection{Outlook for further understanding of the mechanism of corrosion} initiation

Analysing the factors that influence corrosion initiation in concrete is complex, due to the almost countless parameters that may potentially influence corrosion initiation. Thus, a complete analysis is beyond the scope of this short communication. We are convinced that by making the comprehensive and systematically collected data freely accessible to the research community, scholars may use different approaches and techniques for refined analyses. This will promote further discussion and enables corrosion scientists working on chloride-induced corrosion of reinforcing steel in concrete to further understand the mechanism of corrosion initiation in concrete.

\section{Concluding remarks and perspectives}

In line with current open data initiative this short communication presents for the first time a systematic data collection of critical chloride content data from engineering structures obtained with the same test protocol [10]. It documents and highlights the importance of a site-specific statistical distribution of the critical chloride content $C_{\text {crit }}$ for more reliable probabilistic service life modeling and intends to stimulate discussion on this important topic among scholars working in this field. The main conclusions are:

1) The statistical distribution of $C_{\text {crit }}$ can significantly differ from one structure to another and even between members within one structure. Since a wide range of possible influencing factors - such as type of structure, concrete and steel properties and characteristics at the steel-concrete interface - are also documented in the data collection, engineers performing service life modelling now have a basis to select a more adequate statistical distribution as input data for the existing models than by assuming a constant distribution, such as the one given in the fib model code for service life design [22].

2) Systematically reporting $C_{\text {crit }}$ together with corresponding potential influencing parameters will enhance the understanding and promote future discussion of the without doubt important questions related to the mechanism of chloride-induced corrosion initiation in concrete. The proposed data collection allows studying the influence of local conditions at the steel-concrete interface on samples from real structures, which are known to show considerably different characteristics at the steel-concrete interface than samples produced in the laboratory [35].

3) Our results indicate that the role of air voids in promoting corrosion initiation is more complex than previously expected and needs additional considerations such as the moisture state of the concrete. Additionally, $\mathrm{pH}$ changes ahead of the carbonation front were found to significantly influence the susceptibility to corrosion. We recommend further studies to address these important questions.

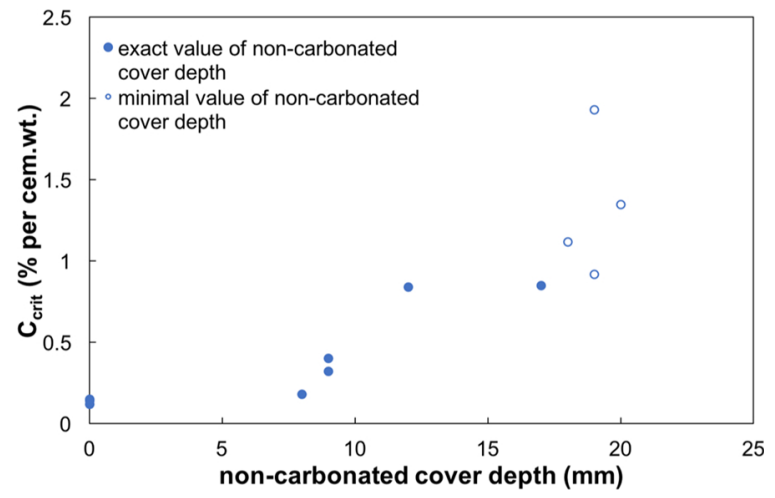

Fig. 6. Comparison of the non-carbonated cover depth with $C_{\text {crit }}$ of one selected structure. The filled circles represent the exact value of non-carbonated cover depth, measured directly at the split sample with Phenolphthalein. The empty circles indicate minimal values of the non-carbonated cover depth. In these cases, the analysed part of the cover concrete did not show any carbonation and the actual non-carbonated cover depth remains unknown (but certainly higher than the given value). 


\section{Data availability}

Raw and processed data are described in detail in a "Data in Brief" paper [11]. The raw data required to reproduce these findings are available to download from [10].

\section{Acknowledgements}

The authors acknowledge the Federal Roads Office Switzerland for funding part of this research project.

\section{References}

[1] British Cement Association, Development of an Holistic Approach to Ensure the Durability of New Concrete Construction, British Cement Association, Crowthorne, UK, 1997.

[2] G. Koch, Cost of corrosion, Trends in Oil and Gas Corrosion Research and Technologies, Woodhead Publishing, Boston, 2017, pp. 3-30.

[3] G.H. Koch, Corrosion Cost and Preventive Strategies in the United States, TurnerFairbank Highway Research Center, Springfield, 2002.

[4] U.M. Angst, Challenges and opportunities in corrosion of steel in concrete, Mater Struct. 51 (2018)

[5] W. Breit, Critical Corrosion Inducing Chloride Content - State of the Art and New Investigation Results, Düsseldorf, Germany (2001).

[6] K.Y. Ann, H.W. Song, Chloride threshold level for corrosion of steel in concrete, Corros. Sci. 49 (2007) 4113-4133.

[7] M.C. Alonso, M. Sanchez, Analysis of the variability of chloride threshold values in the literature, Mater. Corros. 60 (2009) 631-637.

[8] U. Angst, B. Elsener, C.K. Larsen, Ø. Vennesland, Critical chloride content in reinforced concrete - a review, Cem. Concr. Res. 39 (2009) 1122-1138.

[9] U. Angst, $\varnothing$. Vennesland, Critical chloride content in reinforced concrete - State of the art, in: M.G. Alexander, H.-D. Beushausen, F. Dehn, P. Moyo (Eds.), International Conference on Concrete Repair, Rehabilitation and Retrofitting (ICCRRR), CRC Press, Cape Town, South Africa, 2008, pp. 149-150.

[10] C. Boschmann Käthler, U. Angst, B. Elsener, A Data Collection for Critical Chloride Contents for Steel Corrosion in Concrete, ETHZ, Zurich, 2018, https://doi.org/10. 3929/ethz-b-000282371.

[11] C. Boschmann Käthler, U.M. Angst, B. Elsener, A Database of Critical Chloride Contents for Steel Corrosion in Concrete Measured on Samples From Engineering Structures, Data in Brief, (2018) submitted.

[12] U.M. Angst, C. Boschmann, M. Wagner, B. Elsener, Experimental protocol to determine the chloride threshold value for corrosion in samples taken from reinforced concrete structures, J. Vis. Exp. 126 (2017).

[13] Y. Cao, C. Gehlen, U. Angst, L. Wang, Z.D. Wang, Y. Yao, Critical chloride content in reinforced concrete - an updated review considering Chinese experience, Cem. Concr. Res. 117 (2019) 58-68.

[14] U. Angst, M. Wagner, B. Elsener, A. Leemann, P. van Nygaard, Schlussbericht ASTRA AGB 2012/010: Methode zur Bestimmung des kritischen Chloridgehalts an bestehenden Stahlbetonbauwerken, ASTRA, 2016.

[15] RILEM Technical Committee TC 235-CTC, Corrosion Initiating Chloride Threshold Concentrations in Concrete, (2009) http://www.rilem.net/.

[16] L. Tang, J.M. Frederiksen, U. Angst, R. Polder, M.C. Alonso, B. Elsener, R.D. Hooton, J. Pacheco, Experiences from RILEM TC 235-CTC in recommending a test method for chloride threshold values in concrete, Rilem Tech. Lett. 3 (2018) 25-31.

[17] SIA, SIA EN 14630 - Bestimmung der Karbonatisierungstiefe in Festbeton mit der Phenolphtalein-Prüfung, SIA, SIA, Zürich, 2006.

[18] RILEM Technical Committee TC 262-SCI, Characteristics of the steel/concrete Interface and Their Effect on Initiation of Chloride-induced Reinforcement Corrosion, (2014) http://www.rilem.net/.

[19] C. Boschmann Käthler, U. Angst, B. Elsener, Measuring critical chloride contents in structures and the influence on service life modelling, in: R. Caspeele, L. Taerwe,
D.M. Frangopol (Eds.), IALCCE, CRC Press, Gent, 20182018

[20] M. Collepardi, R. Turriziani, A. Marcialis, Penetration of chloride-ions into cement pastes and concretes, J. Am. Ceram. Soc. 55 (1972) 534.

[21] DuraCrete, DuraCrete - Probabilistic Performance Based Durability Design of Concrete Structures, Brite EuRam III, (2000).

[22] fib, Model Code for Service Life Design, International Federation for Structural Concrete (fib), Lausanne, (2006).

[23] L. Tang, L.O. Nilsson, M.P.A. Basheer, Resistance of Concrete to Chloride Ingress: Testing and Modelling, CRC Press, Boca Raton, 2012.

[24] L. Tang, P. Utgenannt, Chloride Ingress and Reinforcement Corrosion in Concrete Under De-icing Highway Environment - a Study After 10 Years' Field Exposure, SP Technical Research Institute of Sweden, Borås (SE), 2007.

[25] P.B. Bamforth, The derivation of input data for modelling chloride ingress from eight-year UK coastal exposure trials, Mag. Concr. Res. 51 (1999) 87-96.

[26] Kv. Breugel, R.B. Polder, M.Rd. Rooij, Long-term Performance of Marine Structures in the Netherlands - Validation of Predictive Models for Chloride Ingress, IALCCE, Taylor \& Francis Group, Delft, NL, 2017.

[27] P. Søren Lundsted, S. Henrik Erndahl, Chloride Ingress in Old Danish Bridges, 2nd ICDC, New Delhi, India, 2014.

[28] U.M. Angst, Predicting the time to corrosion initiation in reinforced concrete structures exposed to chlorides, Cem. Concr. Res. 115 (2019) 559-567.

[29] L. Bertolini, B. Elsener, P. Pedeferri, E. Redaelli, R. Polder, Corrosion of Steel in Concrete - Prevention, Diagnosis, Repair, 2nd ed., Wiley-VCH, Weinheim, 2013.

[30] G. Kapteina, Sensitivity analysis of a service life model linked to chloride induced corrosion focusing on the critical chloride content, in: R. Caspeele, L. Taerwe, D.M. Frangopol (Eds.), IALCCE, CRC Press, Gent, 20182018.

[31] N.R. Buenfeld, G.K. Glass, B. Reddy, R.F. Viles, U. Patent (Ed.), Process for the Protection of Reinforcement in Reinforced Concrete, 2004 USA.

[32] T.U. Mohammed, T. Yamaji, T. Aoyama, H. H, Marine durability of 15-year Old concrete specimens made with ordinary Portland, slag, and fly ash cements, in: V.M. Malhotra (Ed.), SP-199: Seventh CANMET/ACI International Conference on Fly Ash, Silica Fume, Slag and Natural Pozzolans in Concrete, Chennai (Madras), India, 2001, p. 957.

[33] SIA, SIA 262: Betonbau, in, Schweizerischer Ingenieur- und Architektenverein, Zürich (2013).

[34] G. Fagerlund, The Long Time Water Absorption in the Air-pore Structure of Concrete, (1993).

[35] U.M. Angst, M.R. Geiker, A. Michel, C. Gehlen, H. Wong, O.B. Isgor, B. Elsener, C.M. Hansson, R. François, K. Hornbostel, R. Polder, M.C. Alonso, M. Sanchez, M.J. Correia, M. Criado, A. Sagüés, N. Buenfeld, The steel-concrete interface, Mater. Struct. 50 (2017).

[36] Y. Seguí Femenias, U. Angst, B. Elsener, PH-monitoring in mortar with thermallyoxidized iridium electrodes, Rilem Tech. Lett. 2 (2017) 59.

[37] G.K. Glass, N.R. Buenfeld, The presentation of the chloride threshold level for corrosion of steel in concrete, Corros. Sci. 39 (1997) 1001-1013.

[38] G.K. Glass, B. Reddy, N.R. Buenfeld, The participation of bound chloride in passive film breakdown on steel in concrete, Corros. Sci. 42 (2000) 2013-2021.

[39] Y. Seguí Femenias, U. Angst, F. Moro, B. Elsener, Development of a novel methodology to assess the corrosion threshold in concrete based on simultaneous monitoring of $\mathrm{pH}$ and free chloride concentration, Sensors 18 (2018).

Carolina Boschmann Käthler, Ueli M. Angst, Asel Maria Aguilar ETH Zurich, Institute for Building Materials (IfB), ETH Hönggerberg, CH8093 Zurich, Switzerland

Bernhard Elsener ${ }^{\mathrm{a}, \mathrm{b}}$,

${ }^{\text {a }}$ ETH Zurich, Institute for Building Materials (IfB), ETH Hönggerberg, CH8093 Zurich, Switzerland

${ }^{\mathrm{b}}$ University of Cagliari, Department of Chemical and Geological Science, I09100 Monserrato (CA), Italy E-mail address: elsener@ethz.ch.

\footnotetext{
* Corresponding author at: ETH Zurich, Institute for Building Materials (IfB), ETH Hönggerberg, CH-8093 Zurich, Switzerland.
} 